\title{
O sistema pessoal do Tupinambá
}

\author{
Aryon Dall'Igna Rodrigues
}

1. O presente artigo trata de um aspecto marcante do sistema de expressão pessoal de uma língua indígena americana - o Tupinambá (ou Tupí Antigo), falada na costa leste, nordeste e norte do Brasil nos séculos 16 e 17. A documentação básica para a análise científica dessa língua á constituída por gramáticas, vocabulários e textos compostos por missionários e viajantes; os documentos diretamente utilizados neste estudo estão indicados adiante, sob o número 5 .

2. O sistema pessoal do Tupinambá apresenta uma dupla peculiaridade, até agora não documentada claramente para nenhuma outra língua: há distinção morfológica de duas "primeiras pessoas inclusivas" e não há nenhuma distinção entre estas e as "terceiras pessoas". Os prefixos marcadores de sujeito nos verbos são os seguintes, com traduções aproximativas:

$$
\begin{array}{ll}
a- & \text { 'eu' } \\
\text { ere- } & \text { 'você' } \\
\text { oro- } & \text { 'eu e ele(s)' } \\
p e^{-} & \text {'você e ele(s)' } \\
y a- & \text { 'eu e você', 'ele(s)' } \\
o^{-} & \text {'eu, você e ele(s), 'ele(s)' }
\end{array}
$$

Exemplos de ya- e o-:
(1) yané ya'ú 'nós (eu e você) o comemos'
(2) $m a^{\prime} e ́ y a^{\top} u ́$
'um animal o comeu' 
(3) asé osenõy

'nós (eu, você e ele) o chamamos'

(4) payé osenõy

'o pajé o chamou'

'Ele(s)' como tradução de $y a$ - e $o$ - não é bastante preciso: $o$-, significando 'ele(s)' ocorre em verbos transitivos e intransitivos, ao passo que ya-com esse significado ocorre só em verbos transitivos. As construções transitivas oferecem, pois, situações opositivas: $o$ - ocorre quando o sujeito é o foco (o tópico principal) do discurso, enquanto que $y a$ - ocorre quando o sujeito não é o foco (este é o objeto). Exemplo (de Anchieta, G 36v):

(5) morubisába moná oynamíókukár 'o-juiz (foco) mandou-cortar-a-orelha-de o-ladrão'

(6) morubisába moná yaynamíókukár 'o-juiz mandou-cortar-a-orelha-de o-ladrão (foco)'

3. A distinção entre foco e não-foco não foi percebida de maneira assim clara pelos analistas precedentes, mas é a melhor hipótese que podemos postular para explicar as ocorrências de $y a$ - e $o$-com o significado aparentemente comum de "ele(s)"; esta hipótese baseia-se: (a) na discussão de ya-pelos antigos gramáticos, (b) na ocorrência de $y a$ - e $o$-nos textos disponíveis e (c) na coerência interna do sistema pessoal do Tupinambá.

3.1. Anchieta (AG 36v) atribui a ya- 'ele(s)' o significado de sujeito de menor valia que o respectivo objeto e dá os seguintes exemplos:

(7) syé rúba tobayára ya’ú

'os contrários comeram meu pai' (AG 36v)

(8) mõya Pedro yaysu'ú

'a cobra mordeu a Pedro' (AG 36v)

(9) Pedro ta'tra yaynupã

'seu filho (scilicet, de Pedro) açoutou a Pedro' (AG36v)

Mas, a seguir, observa que ya- também se usa em casos em que o sujeito é de maior valia ('Ainda que também se pode usar deste, quando o nominativo é de maior estima', AG 36v), com o que revela irrelevância do critério da maior 
ou menor valia do sujeito; os exemplos então dados são (5) e (6) acima, nos quais a alternância entre $y a$ - e $o$ - se dá, para Anchieta, "secundum subiectam materiam", i. é, segundo a matéria em consideração no discurso. Este é o ponto em que ele mais se aproxima de nossa hipótese do foco.

3.2. Figueira simplesmente menciona esta alternância, sem explicá-la, e dá os seguintes exemplos:

(10) Pedro móya oyuká (F 99)

'Pedro matou uma cobra'

(11) Pedro móya yayuká (F 99)

'Pedro matou uma cobra'

(12) oerasó temõ sapỉá ibákipe tupána syé rúba mã (F 99)

'oxalá (temõ..mã) levasse (oerasó) Deus (tupána)

cedo (sapi’á) a meu pai (syérúba) para o céu (íbákipe)!'

(13) yarasó temõ sapìáá ṫbákipe tupána syé rúba mã (F 99)

mesmo significado que (12)

Acrescenta que (13) é melhor que (12), informação incompatível com a hipótese de Anchieta (o sujeito 'Deus' seria de "maior valia" que o objeto "meu pai"), mas que satisfaz plenamente a hipótese do foco (a possibilidade de "meu pai" ser o foco do discurso é muito maior do que a de "Deus" ser o tópico principal).

3.3. A grande maioria de ocorrências documentadas de orações transitivas com sujeito e objeto de " 3 a pessoa" tem sujeito focal. Alguns casos mais de objeto focal encontram-se nas composições poéticas de Anchieta. Em todos estes casos o prefixo marcador de sujeito é $y a$-:

(14) opá emonã tekwára yané ratá yayá(r) rõ (AP 288)

'pois (rõ) nosso fogo (yanératá) recebe (yayár) todos os que vivem assim (opá emonã tekwára)' (dito por um diabo a respeito dos pecadores: estes são o foco do discurso, ao passo que o sujeito 'nosso fogo' é incidental)

(15) yaymoreawsú(b) ro’’̇ (AP 317)

'o frio $\left(r o^{\prime} i\right)$ fê-lo sofrer' (num poema sobre o Menino Jesus, foco e, aqui, objeto; o sujeito 'o frio' é incidental) 
(16) yaypópwáratã... yaynupãnupã (AP 327)

'amarraram-lhe fortemente as mãos... surraram-no' (numa composição sobre Cristo, foco e objeto)

(17) yaypóasásá(b) (AP 328)

'transpassaram-lhe [com cravos] as mãos' (como 16)

(18) isí n-imemérasṫy na-suwty n-imara'ári n-yaymomarãpotári pitáyĩ morawsubára (AP 317)

'sua mãe (isît) não teve dor de parto (n-imemt̂trasty), não sangrou (na-suwty), não ficou doente (n-imara'ári), não quis fazê-la sofrer (n-yaymomarãpotári) o menininho misericordioso (pitáyĩ morawsubára) (o foco é 'sua mãe', sujeito das três primeiras orações [nenhuma com verbo transitivo], mas objeto da quarta).

3.4. O Vocabulário na Língua Brasílica oferece breve discussão o problema da distinção entre $y a$ - e $o$ - no verbete "Eclypsar se a lua", para o qual dá:

(19) yasí ma'éya'ú (V 1.108)

('um animal come a lua')

(20) ma'é yasí ya úu (V 1.108)

('um animal come a lua')

(21) yasí ma'é o’ú (V 1.108)

('o animal come a lua')

(22) ma'é yasí o’ú (V 1.108)

('o animal come a lua')

E acrescenta: "Estes são dos mais escuros termos de falar que ha nesta lingoa, porq. querem dizer que a lua he comida dalgũa coisa, e são tam ambiguos q. iuntamente querem dizer que ella he a que come algũa cousa. ... O eclypse da Lua dizẽ elles q. a come algũa fera do Ceo”. (V 1.108)

Supomos que (19) e (20) têm a lua (objeto) como tópico principal - o que seria a situação mais comum ao explicar-se o que acontece com ela no eclipse -, ao passo que (21) e (22) têm o animal (sujeito) como foco.

3.5. Mais um argumento para a hipótese do foco é o uso "impessoal" de ya-, registrado por Anchieta: "Também se usa desta primeira plural por terceira impersonaliter, ut yajucâ, matão, sem ter nominativo expresso" (AG 36v). O exemplo: 
(23)

$$
\begin{aligned}
& \text { yayuká } \\
& \text { 'matam', aliás 'matam-no', }
\end{aligned}
$$

é um caso típico de sujeito não focal.

Outros exemplos análogos ocorrem no Catecismo na Língua Brasílica:

(24) emonã tekwárwéra yaype'á (C 128)

'o que tiver estado assim (emonã tekwárwéra) [casado contravontade] é separado' (na tradução do Catecismo: 'há-se de apartar')

(25) ...yaype'á yẽ aypóba'é amõ resé imomená (C 131v)

'são separados (yaype'á) sem mais (yê) esses (aypóba'ê) e casados (imomená) com outras (amõresê) (no Catecismo:'apartamos aos taes, e casamolos com outras')

4. No conjunto de seis prefixos marcadores de sujeito podemos distinguir:

(a) formas que manifestam a oposição entre o falante e o ouvinte: $a$-, ere-, oro-, pe-;

(b) formas que não manifestam essa oposição, porque incluem ou excluem tanto o falante como o ouvinte: $y a-, o-$;

(c) formas em que uma $3^{\text {a }}$ pessoa está incluída necessariamente: oro-, pe-, $o-$;

(d) formas que excluem a $3^{\text {a }}$ pessoa, ou em que esta pode estar implícita, mas não é focal: $a-$, ere-, ya-.

Com base nessas distinções, podemos construir uma matriz de componentes "semânticos" que ponha em evidência os fatores necessários e suficientes

\begin{tabular}{|c|c|c|c|c|}
\hline & & \multicolumn{2}{|c|}{ oposição } & $\mathrm{F} / \mathrm{O}$ \\
\hline & & \multicolumn{2}{|c|}{+} & \multirow{2}{*}{-} \\
\hline & & $\mathrm{F}$ & $\mathrm{O}$ & \\
\hline & - & $a^{-}$ & ere & va- \\
\hline $3 \mathrm{~F}$ & + & oro- & pe- & $\mathrm{O}^{-}$ \\
\hline \multicolumn{5}{|c|}{$\mathrm{F}=$ falante } \\
\hline \multicolumn{5}{|c|}{$\mathrm{O}=$ ouvinte } \\
\hline $3 \mathrm{~F}$ & & a foc & & \\
\hline
\end{tabular}
para caracterizar todas as formas: 
Essa matriz mostra que $y a$ - e $o$ - significam ambos a neutralização da oposição entre o falante e o ouvinte, oposição que se dá quando os dois estão presentes ("nós inclusivo") e quando os dois estão ausentes ("ele[s]"); a distinção entre $y a$ - e $o$-repousa exclusivamente na presença ou ausência de uma terceira pessoa focal.

A neutralização da oposição entre o falante e o ouvinte pode ser representada numa árvore gerativa, em que a confluência de ramos indica uma só saída para situações semanticamente distintas:

$\mathrm{F}$

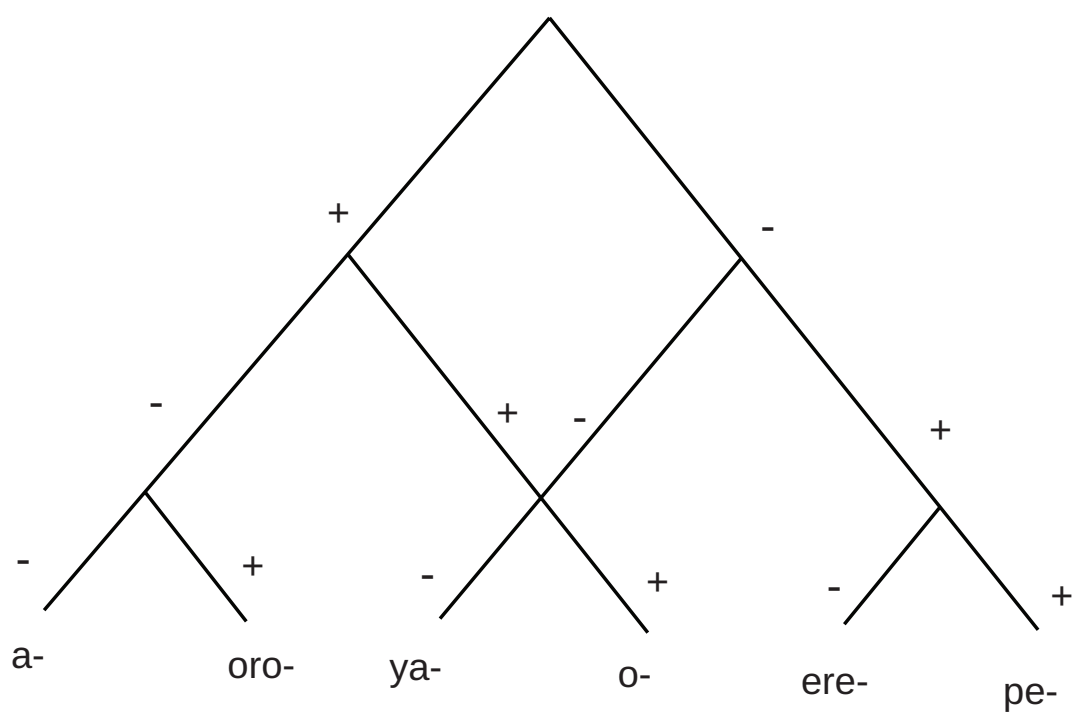

